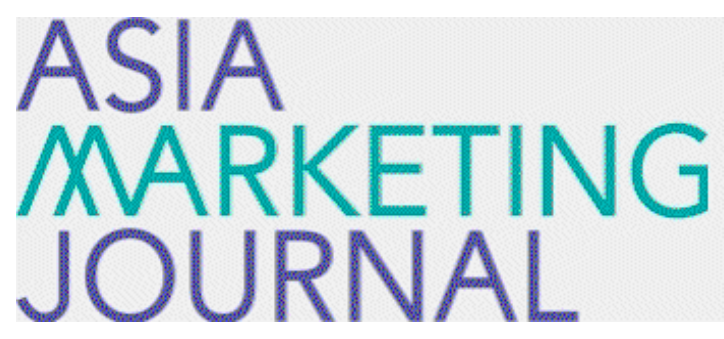

ASIA MARKETING JOURNAL

Volume 17 | Issue 1

Article 6

4-30-2015

\title{
Sales Control Systems and Behavioral Responses
}

Jaewon Yoo

Follow this and additional works at: https://amj.kma.re.kr/journal

Part of the Marketing Commons

\section{Recommended Citation}

Yoo, Jaewon (2015) "Sales Control Systems and Behavioral Responses," Asia Marketing Journal: Vol. 17 : Iss. 1 , Article 6.

Available at: https://doi.org/10.15830/amj.2015.17.1.123

This Article is brought to you for free and open access by Asia Marketing Journal. It has been accepted for inclusion in Asia Marketing Journal by an authorized editor of Asia Marketing Journal. 


\title{
Sales Control Systems and Behavioral Responses: Mediating Role of Regulatory Focus and Moderating Role of $\mathrm{P}-\mathrm{O} \mathrm{Fit}^{*}$
}

\author{
Jaewon Yoo**
}

Built on regulatory focus theory, this article develops a research model proposing the relationship between management controls (outcome, activity and capability), sales employees' prevention and promotion focus and their behavioral responses (feedback seeking from different sources and relationship investment). The model also suggests that salesperson perceived organizational fit ( $\mathrm{P}-\mathrm{O}$ fit) contributes by influencing the situational self-regulatory mechanism based on regulatory fit theory.

To analyze the data, a structural equation model procedure using LISREL 8.5 was employed. To access the potential common method bias, the MV" marker method was applied using a scale theoretically unrelated to at least one scale in the analysis as the MV marker.

The results showed that the greater the salesperson's perceived activity control system, the greater the extent of employee prevention focus. The findings also showed that output control and capability control system are positively related to the promotion focus of salespeople. Salespeople's prevention focus relates negatively to the relational investment and positively to organization feedback seeking. The results indicate that salespeople who have promotion focus exhibit the predicted positive influence on their relationship investment.

A significant contribution of this research framework is suggesting salesperson regulatory focus as a mediator and its' effects on different types of sales-related behaviors. The author suggests that the motivational orientations of salespeople play key roles in shaping feedback seeking behaviors from different sources; broadly, that employees with a promotion focus will be more sensitive to customers' feedback, and employees with a prevention focus will seek more feedback from the organization. Furthermore, salespeople with a promotion focus will invest more resources to build relationships with customers than salespeople with a prevention focus. This research also explains the moderating role of person-organization fit on the effect of salespeople's regulatory focus and behavioral responses based on regulatory fit theory

Key words: Management control systems, Prevention focus, Promotion focus, Feedback seeking, Relational investment, $\mathrm{P}-\mathrm{O}$ fit

\footnotetext{
* This work was supported by the National Research Foundation of Korea Grant funded by the Korean Government (NRF-2013S1A5A8020578)

** Assistant Professor of Entrepreneurialship and Small Business, School of Business, Soongsil University (yjw1774@ssu.ac.kr)
} 


\section{Introduction}

Many organizations have seen a shift in resource allocation from marketing to sales (Websteret al. 2003) as companies recognize that sales activities are crucial to the attainment of marketing's top priorities (Onyemah 2005). Accordingly, research attention has focused on sales management control and several organizational factors associated with superior salesperson performance (Lee and Ji, 2013; Pierceet al. 2006).

A firm's management control system is often recognized as an important management tool that affects salesperson behaviors and outcomes (Oliver and Anderson 1994). The manager's control system communicates powerfully what is important and how salespeople should behave. Salespeople are likely to use the control system as a perceptual screen to filter their own evaluations of their sales performance (Lord and Maher 1990).

Challagalla and Shervani (1996) note three types of formal supervisory control systems (output, capability, and process control) to direct employees' job-related outcomes. Interestingly, empirical studies focusing on the effects of control have uncovered some unexpected and ambiguous findings (Challagalla and Shervani 1996). Recent research on the regulatory focus theory (RFT) suggests that people often face decisions between stability (prevention focus) and change (promotion focus). They may need to decide whether to continue a current course of action or undertake a different action or to decide whether to keep an object they have or exchange it for another one (Higgins 1997; 1998). While progress has been made in understanding sales management control and self-regulatory theory, several research questions remain in better understanding how management control systems may be linked to salespeople's regulatory focus and different types of sales-related behavior. This research offers new insights into the sources of different sales behaviors by considering the impact of sales management control on salespeople's regulatory focus. Specifically, this study suggests that sales force regulatory focus is primed by the sales control system. The promotion system is derived from outcome and capability control and employs accomplishing behavior. It is sensitive to the presence and absence of positive outcome. The prevention system is derived from activity control and employs goal-responsible behavior.

Two basic assumptions for developing this research framework are suggested. First, management control systems can be regarded as situational cues of regulatory focus. According to Higgins (1998), a person's differing focus can be seen either as a dispositional or situational feature. In organizational settings, specific climates developed by leaders may capture such situational cues (Zohar 2000). Second, salespeople's regulatory focus is shaped at the group level and dominates a salesperson's self-regulation 
derived from his or her personality. Shah et al. (2004) focus on the group-level and social identitybased regulatory focus, which are referred to as collective regulatory focus. So collective regulatory focus can be defined as promotion- or prevention-related goals and strategies that have become part of a group's identity, and direct individual group members toward promotionor prevention-oriented behavior. Thus, although collective regulatory focus can be seen as a group norm or group strategy, it is a norm/ strategy that operates via the social identity of the group members through the process of so- $^{-}$ cial categorization.

Based on the regulatory fit theory, the moderating role of perceived organizational fit is also explored. Regulatory fit makes people "feel right" about what they are doing and strengthens engagement in goal-directed behaviors (Higgins 2000). Higgins (2000) suggests that greater person - environment regulatory focus fit heightens work motivation, while regulatory focus theory also suggests that within different states of person - environment fit, employees may cause different behavioral outcomes.

\section{Theoretical Background}

\subsection{Regulatory Focus Theory}

Regulatory focus theory (RFT; Higgins 1997) distinguishes between two distinct regulatory orientations: promotion focus and prevention focus. People with a promotion focus are sensitive to the absence and presence of positive outcomes; they are concerned with growth, accomplishments, and aspirations. In contrast, those with a prevention focus are sensitive to the absence and presence of negative outcomes; they are concerned with safety, responsibilities, and obligations. According to RFT, any goal may be pursued with a promotion or a prevention focus (Kim 2014).

Fundamentally, a person's differing focus can be seen either as a dispositional or situational feature. According to Higgins (1998), differences in chronic focus are attributable to the lasting effect of different learning styles and standard values in the course of socialization.

In another instance, the regulatory focus can be determined by the situation in which an individual finds him or herself, such as the possibility of having to buy a reliable household product versus wanting to purchase a representative status object (so-called situational focus; Förster et al. 1998; Higgins et al. 1994). However, Higgins (1997) stated that situational framing can also influence individuals in such a manner as to instill one focus or the other. This study examines regulatory focus as a situational state that can be induced by the interdependency structure of a group task.

Over the past few years, regulatory focus has increasingly been studied in group contexts (e.g., 
Faddegon et al. 2008; Faddegon et al. 2009; Jonas et al. 2010; Rietzschel 2011; Shah et al. 2004). These studies have shown that groups can develop or adopt a joint focus on promotion or prevention. Clearly, whether the joint focus of a group is on promotion or prevention can have important implications for the performance of many groups and work teams (Faddegon et al. 2009).

For instance, when a situation is framed in terms of achievement and accomplishments (e.g., production), employees may be inclined to adopt a promotion focus. If, on the other hand, a situation is framed in terms of accurate and errorfree task completion (e.g., completing a task safely), then a prevention focus may be adopted. Levine et al. (2000) have shown that group members' regulatory focus strategies can be categorized as having either a promotion or prevention focus, depending on how the outcomes of a joint task are framed (i.e., as gains vs. non-gains or as losses vs. non-losses).

In organizational settings, specific climates developed by leaders may capture such situational cues (cf. Zohar 2000). In this case, situational cues take on added importance as employees seek out information related to behavioral expectations and their potential consequences (Scott and Bruce 1994).

Shah et al. (2004) focus on group-level and social identity-based regulatory focus, which are referred to as collective regulatory focus. Collective regulatory focus can be defined as promotion or prevention-related goals and strategies that have become part of a group's identity, and direct individual group members toward promotion- or prevention-oriented behavior. Faddegon et al. (2008) examine how the "collective" promotion or prevention focus of a group influences the behavior of individual group members based on social identity theory and self-categorization theory. Faddegon et al. (2009) showed that chronic regulatory focus affected creative group performance in an anagram task. Rietzschel (2011) suggests that the levels of team's collective promotion focus will positively predict the specific aspects of team innovation such as idea generation and idea promotion activities; the opposite relationship should hold for prevention focus.

\section{Research Model and Hypotheses}

According to Lord and Maher (1990), salespeople are likely to use their control system as a perceptual screen to filter their own evaluation of their sales performance. However, no attempt to investigate how sales control systems influence salesperson self-regulation formation has been made so far.

In organizational settings, situational cues take on added importance as employees seek information related to behavioral expectations and 
〈Figure 1〉 Research Model and Hypotheses

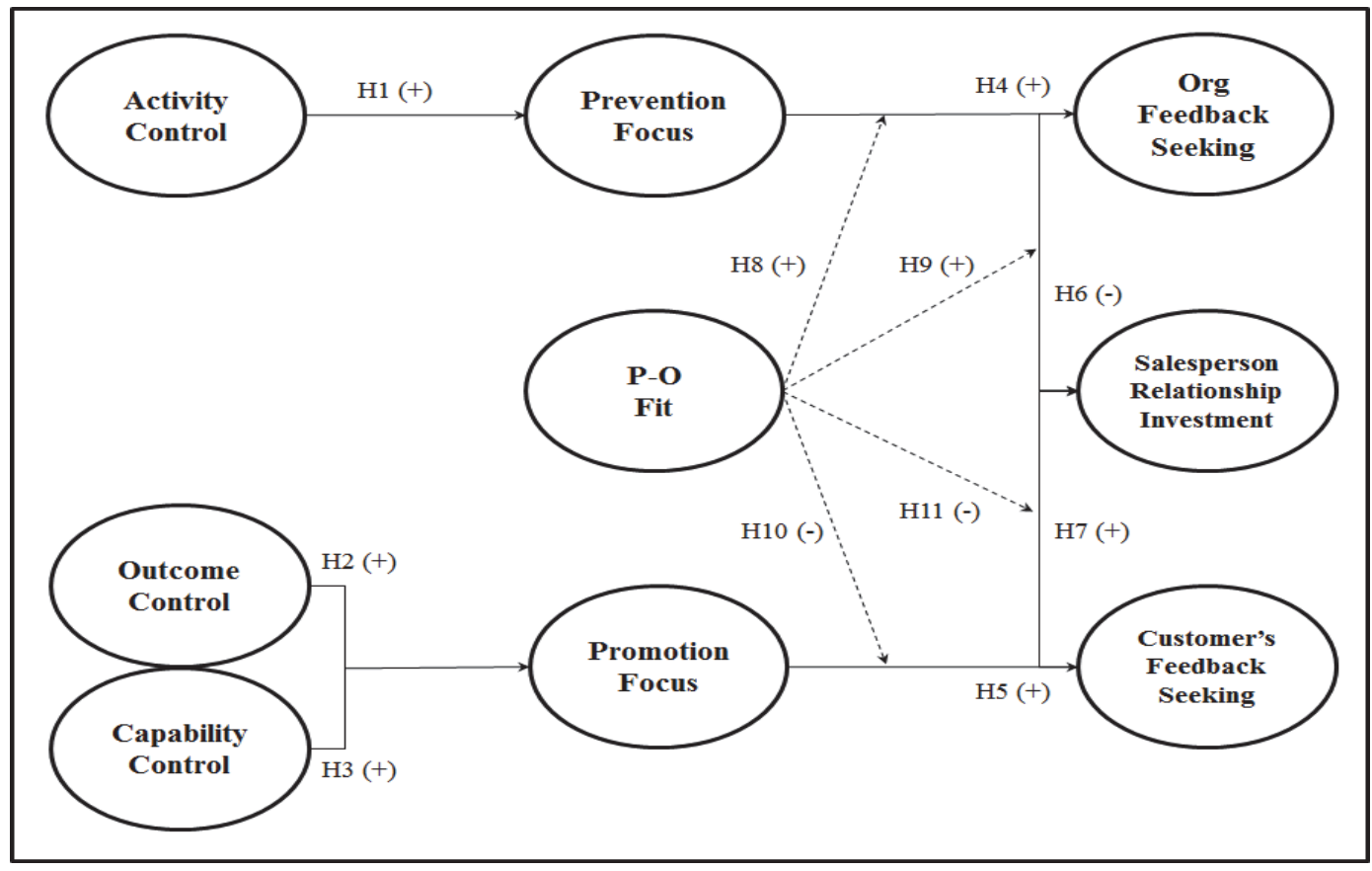

their potential consequences (Scott and Bruce 1994). Situational cues that emphasize nurturance needs, attainment of ideals, and potential gains tend to induce a promotion mindset, whereas situational cues that emphasize security needs, fulfillment of obligations, and potential losses tend to induce a prevention mindset (Higgins 1997; 1998). Based on the relationship between management control systems and sales force regulatory focus, the cause of differences in salesperson behavioral responses can be inferred.

\subsection{Salespeople's Response to Management Control Systems}

Management control systems are used by managers to encourage the attainment of $\mathrm{de}^{-}$ sired organizational objectives (Challagallaand Shervani 1996). Management control in organizations concerns the efforts of managers to influence the behavior and activities of personnel to accomplish the objectives of the organization (Jaworski et al. 1993). Scholars concur on this general view of management control but differ as to the dimensions and types of control (Piercy et al. 2006). Anderson and Oliver (1987) conceptualized two types of control systems (outcome control and behavior control).

When using outcome control, the sales manager is concerned with the results produced by salespeople in terms of sales, market share, and profit contribution (Oliver and Anderson 1994). 
Anderson and Oliver (1987) defined behavior control in terms of (1) specific sales management activities and (2) the extent to which managers perform the activities. Managers employing sales management behavior control are involved to a great extent in monitoring salespeople; directing salespeople's activities; evaluating salespeople on an input basis, employing subjective and more complex performance measure; and rewarding salespeople with a substantially higher proportion of fixed salary compared to incentive compensation.

Due to the broad nature of behavior control systems, Challagalla and Shervani(1996) determined the need to further divide behavior control systems into two components: 1) activity control and 2) capability control. Specifically, activity control addresses the monitoring and supervision of activities in pursuit of sales (e.g., making sales calls, delivering proposals, presentations, and customer demonstrations, etc.). Salesperson activity control may be perceived by the salesperson as controlling or manipulative of his or her behavior since it involves more prescriptive direction (from the manager) as to how the selling job should be performed (Mallin and Pullins 2009).

According to regulatory focus theory, prevention-focused individuals are likely to value safety and follow rules (Kark and Van Dijk 2007). Furthermore, prevention-focused individuals are concerned with what they ought to do, acting out of obligation and in accordance with $\mathrm{ex}^{-}$ pectations (Higgins 1997; 1998). Shah and Higgins (1997) suggest that a prevention focus involves construal of achievement goals as responsibilities whose attainment brings security. Commitment to these security goals is characterized by doing what is necessary. Neubert et al. (2008) also suggest that the leader's behavior that is focused on directing and structuring subordinates' tasks is related with employees' prevention focus.

Oliver and Anderson (1995) explain that riskavoiding salespeople may wish to shift their efforts to those sales team activities with greater stability (account maintenance, specification, and term) or to product lines with more predictable demand characteristics. Task stability would appear to argue for a behavior control approach (especially activity control) as the sales process is more orderly and potentially measureable (Oliver and Anderson 1995). Firms that possess a prevention focus are likely to opt for process-based control systems, which specify requisite behaviors that firms must adhere to. There are clean norms as to what is and what is not acceptable behavior, and deviation from these norms invites penalties such as activity control (Das and Kumar 2011).

Thus, considerable monitoring of salespeople's activities and results, high levels of management direction, and intervention in the activities of salespeople make salespeople more focused on avoiding inappropriate behavior and fulfilling required behavior from the manager's 
perspective.

Hypothesis 1: Activity control systems positively impact salesperson prevention focus.

Outcome control uses incentives to reward salespeople in direct proportion to their sales outcomes (e.g., sales volume). Outcome control represents a "hands-off" approach to managing salespeople in that they are given a great deal of autonomy and independence to perform their duties and are compensated for the output they achieve.

According to Hofstede (1980), people in lowuncertainty avoidance cultures (promotion focus) relish risk and challenging work. Faddegonet al. (2008) suggest that group members need to be creative and have to take risks (e.g., a product development team), and thus a joint focus on promotion is most suitable. Shah and Higgins (1997) suggest that a promotion focus involves construal of achievement goals as aspirations whose attainment brings accomplishment. Das and Kumar (2011) also suggest that firms with a promotion regulatory focus are likely to emphasize outcome-based control systems for managing inter-partner conflict.

Thus, salespeople in outcome-based control are more concerned about achieving their sales goals and put more effort into increasing their sales performance, which is the main criterion for evaluation.
Hypothesis 2: Outcome control systems positively impact salesperson promotion focus.

Compared to activity control, capability control is designed to develop and reward salesperson selling skills and has been suggested to impact intrinsic motivation primarily by promoting an enjoyable task environment (Challagalla and Shervani 1996). Capability control enhances salespeople's perceived competence (Challagalla and Shervani 1996) and allows salespeople to apply learned skills in a more autonomous fashion (Kohliet al. 1998). Like output control, the ultimate goal of capability control is to improve the salesperson's performance outcome (Miao et al. 2007).

According to Higgins et al. (1994), the promotion focus of strong ideals leads to greater accomplishment-related strategies for selfregulation. Thus, capability control may be perceived as an endorsement of promotion-focused assumptions, which then encourages goal-oriented behavior for enhancing outcomes by eliciting a promotion focus from salespeople. Thus, under capability control, salespeople are more concerned about achievement by adopting a promotion focus.

Hypothesis 3: Capability control systems positively impact salesperson promotion focus. 


\subsection{Regulatory Focus and Sales Force Behavior}

This study suggests the effect of management control systems on employees' behavioral responses through the mediation of sales force regulatory focus. Wu et al. (2008) suggest that prevention focus emphasizes minimal goals, such as minimizing the "risk" of a risk-return dilemma. In the attempt to fulfill safety or security needs, prevention-focused individuals strive to bring themselves into alignment with their “ought” selves (Higgins 1997). As a result, they are attentive to the absence or non-absence of negative outcomes and are more oriented toward avoidance of loss or failure.

A key purpose of activity control is to ensure that organizational members focus their efforts on actions that supervisors deem important for the long term effectiveness of the organization (Challagalla and Shervani 1996). From the perspective of the salesperson in activity control systems, negative outcomes can be disobedience from behavioral guidelines and misfit with their organization's behavioral expectations. The most important interaction in activity control systems may occur in the relationship between salespeople and their organizations. Thus, salespeople with a prevention focus are more sensitive to their organizational response feedback because of the characteristics of a prevention focus.

Hypothesis 4: Salesperson prevention focus positively impacts a salesperson's organizational feedback seeking behavior.

In contrast, when individuals experience a promotion focus, attention is predominantly allocated to maximal goals, such as maximizing the "return" in a risk - return dilemma. To fulfill nurturance needs, promotion-focused individuals strive to bring themselves into alignment with their ideal selves (Higgins 1997). As a result, they are attuned to the presence or non-presence of positive outcomes and are drawn toward the pursuit of approach-oriented ends, such as gains or success.

The ultimate goal of capability control and output control is to improve the salesperson's outcome performance (Miao et al. 2007). From the perspective of a salesperson in activity and output control systems, the desired outcomes and gains can be defined as sales volume (Fanget al. 2005). In this case, the most important interaction may occur in the relationship between salespeople and customers. Thus, salespeople with a promotion focus are more sensitive to their customer responses feedback because of the characteristics of a promotion focus.

Hypothesis 5: Salesperson promotion focus positively impacts a salesperson's customer feedback seeking behavior.

A seller's relationship investment resembles specific assets in channels literature (Heide and 
Stump 1995) and refers to the time, effort, and resources that sellers invest in building stronger relationships (Palmatier et al. 2006). Such investments often generate expectations of reciprocation that can help strengthen and maintain a relationship. Therefore, they positively influence relational mediators (Ganesan 1994).

People with a promotion focus regulate their behavior for advancement, aspirations, and accomplishments. In contrast, people with a prevention focus are concerned with the $a b^{-}$ sence or presence of negative outcomes. They orient their behavior toward protection, safety, and responsibilities (Higgins 1997; 1998). Zhou and Pham (2004) also found that individuals are differentially sensitive to gains and losses depending on whether a decision task evokes a promotion or a prevention focus.

In the context of relationship building, secure investment alternatives often only provide small returns, while riskier investment alternatives have the potential for higher returns along with the danger of high losses (Florack and Hartmann 2007). Thus, salespeople who have high promotion focus will invest more effort for higher returns (sales growth) and prevention-focused salespeople will spend less input because of the potential loss.

Hypothesis 6: Salesperson prevention focus negatively impacts a salesperson's relationship investment.
Hypothesis 7: Salesperson promotion focus positively impacts a salesperson's relationship investment.

\subsection{Moderating Effects of Perceived Organizational Fit on Sales Force Behavior}

In an organizational context, organizational behavior and marketing researchers have approached about the notion of fit between worker and environment in several ways. This research examined $\mathrm{P}-\mathrm{O}$ fit as a person's perception of his or her compatibility with an organization's culture and members.

Although regulatory focus relates to the goals to be pursued, an equally important consideration is the means available in their pursuit, as fit or misfit between the two can influence many aspects of workplace functioning.

Regulatory fit has been described as the mechanism that explains how employees adapt to the demands of their work situation (Lee and Aaker 2004). In particular, a leader's pattern of behavior is a salient work-environment cue that is likely to evoke a promotion or prevention focus in organizational members (Brockner et al. 2004). Although previous research on regulatory focus has provided important insights on the role of dispositions and states in influencing goals, the role of situational characteristics has been relatively neglected, even though this is an area described as an important focus 
for future research (Wallace and Chen, 2006). One prominent factor that can help explain situation-induced regulatory focus in organizational settings is the employee's perceived congruence with their work environment such as P-O fit. Specifically, lower perceived fit with the organization has a better regulatory fit for salespeople with a promotion focus than for individuals with a prevention focus because lower perceived fit with the organization gives salespeople with a promotion focus the opportunity to engage in behavior that fits their regulatory needs, such as sales outcome-oriented behavior (achievement and accomplishment). Conversely, higher perceived fit with the organization offers a better regulatory fit for salespeople with a prevention focus than for salespeople with a promotion focus because a high level of $\mathrm{P}-\mathrm{O}$ fit allows salespeople to show behavior that fits the regulatory needs of salespeople with a prevention focus, namely, a focus on safety and security, such as organization-oriented behavior.

For instance, if salespeople have a high prevention focus, they will follow their organizational rules and only show organizationally required behavior because prevention-focused individuals are concerned with responsibilities and safety and focus on the presence or absence of negative outcomes (Shah et al.1998). Thus, if salespeople experience more fit with their organization, their motivation for responsibility may also be enhanced. Thus, salesperson with a prevention focus will express more organiza- tional feedback seeking behavior and less salesperson relationship investment efforts.

Hypothesis 8: The effect of prevention focus on a salesperson's organizational feedback seeking behavior is stronger, when salesperson $\mathrm{P}-\mathrm{O}$ fit is high than when salesperson $\mathrm{P}-\mathrm{O}$ fit is low.

Hypothesis 9: The effect of prevention focus on a salesperson's relationship investment are weaker, when salesperson $\mathrm{P}-\mathrm{O}$ fit is high than when salesperson $\mathrm{P}-\mathrm{O}$ fit is low.

Salespeople who have a promotion focus may exhibit more outcome-oriented behavior, and their outcomes are accomplished by interactions with customers. However, when salespeople have higher perceived fit with their organizations, they are also concerned about their organizational well-being. In this case, salespeople can experience the conflicts and ambivalences due to the differences in their goal orientations (customer-oriented behavior for better outcomes vs. organizational-oriented behavior due to high $\mathrm{P}-\mathrm{O}$ fit). Because of limitation of $\mathrm{re}^{-}$ sources, salespeople with a high promotion focus may reduce customer-relationship investment and customer feedback seeking and increase organizational feedback seeking due to their concern about their organizational well-being.

Thus, salespeople with a high promotion focus and $\mathrm{P}-\mathrm{O}$ fit may reduce customer-relationship investment and customer feedback seek- 
ing behavior due to the experience of goal-orientation conflicts.

Hypothesis 10: The effect of promotion focus on a salesperson's customer's feedback seeking behavior is weaker when salesperson's $P-O$ fit is high than when a salesperson's $P-O$ fit is low.

Hypothesis 11: The effect of promotion focus on a salesperson's relationship investment is weaker when the salesperson's $P-O$ fit is high than when a salesperson's $P-O$ fit is low.

\section{Research Methodology}

\subsection{Measures}

All measures are adapted from or developed based on prior research. Individual measurement items for the constructs are listed in Appendix A.

To measure output, activity, and capability control, this study used 15 items drawn from Miaoet al. (2007). Five items were adopted to measure each type of control. The 12-items regulatory focus at work previously utilized by Wallace and Chen (2005) and Wallace et al. (2009) was used. Wallace and Chen (2005)'s measure contains two factors, each with six items, (1) promotion focus and (2) prevention focus. In line with regulatory focus theory, promotion items that capture employees' behav- ioral manifestations are likely to promote positive outcomes at work, whereas prevention items capture behavioral manifestations that are likely to prevent negative outcomes at work. Personorganization fit was assessed using a scale developed by Netemeyer et al. (1997) that measures the congruence of personality traits, beliefs, and values of an individual employee with the culture, strategic needs, norms, and values of his/her organization (based on employee perceptions of this fit). Four items asked service workers to assess the fit between their personal values and the organization's values. Feedback seeking was measured with a 6 -item scale adapted from Callister et al. (1999). One scale measured feedback seeking from supervisor and the other measures feedback seeking from customers. Respondents indicated the extent to which statements about feedback seeking matched their experiences on 7-point scales. To measure customer relationship investment, this study used three items of De Wulf et al.'s research (2001) that measures the extent to which service employees devote resources, effort, and attention aimed at maintaining or enhancing relationship with regular customers. All items used a response scale ranging from 1 , "strongly disagree" to 7, "strongly agree."

\subsection{Sampling Procedure and Data Collection}

Data for the study were collected from a 
cross-sectional sample of retail bank and insurance companies in South Korea. The sample contained responses from salespeople. All the organizations involved in the data collection offered services and directly sell service products to customers.

The instrument was prepared in English and then translated into Korean. It was checked for accuracy in line with conventional back-translation processes. Data were collected onsite from each participating bank and insurance company. The sample for the study was drawn with the help of chief executive officers (CEOs) who worked for 10 top-ranked banks and 15 topranked insurance companies headquartered in Seoul. The initial contact was letters to top managers, explaining the purpose of the survey and asking them to persuade their branch managers to participate in the survey. Four out of 10 CEOs in the banking industry and 8 out of $15 \mathrm{CEOs}$ in the insurance industry agreed to ask their branch managers to participate. Based on the list of branches suggested by the CEOs, branch managers were asked to help with survey administration.

An interviewer scheduled appointments with branch managers as informants, who then introduced the interviewer to the other employees at their branches. The interviewer presented the respondents with the survey questionnaires and collected the questionnaires upon completion.

\subsection{Sample Characteristics}

Questionnaires were distributed to 750 frontline employees across several banks and insurance companies. Of these, 543 usable questionnaires were returned, a response rate of $72.4 \%$ (with the interviewer presence certainly aiding this response rate). Twenty-five questionnaires were deleted because 6 were internal employees with no contact with customers, and $19 \mathrm{re}^{-}$ spondents did not completely fill out the questionnaires (adjusted response rate $=69.07 \%$ ). The employee sample was $67.2 \%$ female, with an average age of 35 years and less than 8-year tenure in their current positions, and $48.5 \%$ of the sample had a university degree.

\section{Research Findings}

\subsection{Measurement Model Analysis and Results}

To analyze the data, a structural equation model procedure using LISREL 8.5 was employed (Jöreskog and Sörbom 1996). Reliabilities of the individual measurement scales were assessed using Cronbach's coefficient a and Fornell and Larker's (1981) composite reliability formula. The average variance extracted, composite reliability calculations, and items appear in Appendix A. The measurement model in this study con- 
〈Table 1〉 Measure Correlations, Average Variance Extracted and Composite Reliability

\begin{tabular}{|c|c|c|c|c|c|c|c|c|c|}
\hline & $\mathrm{OC}$ & $\mathrm{AC}$ & $\mathrm{CC}$ & PREF & PROF & OFS & CFS & RI & $\mathrm{POF}$ \\
\hline $\mathrm{OC}$ & $\begin{array}{c}.888 \\
(.727)\end{array}$ & $-0.447^{* *}$ & $0.324^{* *}$ & $-0.372^{* *}$ & $0.367^{* * *}$ & $-0.163^{* *}$ & $0.255^{* *}$ & $0.397^{* * *}$ & $-0.121^{* *}$ \\
\hline $\mathrm{AC}$ & $-0.431^{* *}$ & $\begin{array}{c}.942 \\
(.805)\end{array}$ & $-0.481^{* *}$ & $0.316^{* *}$ & $-0.362^{* *}$ & $0.205^{* *}$ & $-0.173^{* *}$ & $-0.345^{* *}$ & $0.018^{* * *}$ \\
\hline $\mathrm{CC}$ & $0.368^{* *}$ & $-0.464^{* *}$ & $\begin{array}{c}.899 \\
(.691)\end{array}$ & $0.331^{* *}$ & $-0.469 * *$ & $0.242^{* *}$ & $-0.301^{* *}$ & $-0.402^{* *}$ & $0.124^{* *}$ \\
\hline PREF & $-0.359 * *$ & $0.323^{* *}$ & $0.338 * *$ & $\begin{array}{c}.930 \\
(.728)\end{array}$ & $-0.647^{* *}$ & $-0.078^{* *}$ & $-0.325^{* *}$ & $-0.431^{* *}$ & $0.184^{* *}$ \\
\hline PROF & $0.374^{* *}$ & $-0.349 * *$ & $-0.455^{* *}$ & $-0.631^{* *}$ & $\begin{array}{c}.912 \\
(.677)\end{array}$ & & $-0.207^{* * *}$ & $0.281^{* *}$ & $-0.113^{* *}$ \\
\hline OFS & $-0.152^{* *}$ & $0.213^{* *}$ & $0.250 * *$ & $-0.068^{* *}$ & $-0.195^{* *}$ & $\begin{array}{c}.915 \\
(.844)\end{array}$ & & $-0.173^{* *}$ & $-0.210^{* *}$ \\
\hline $\mathrm{CFS}$ & $0.263^{* *}$ & $-0.162^{* *}$ & $-0.288^{* *}$ & $-0.312^{* *}$ & $0.289^{* * *}$ & $-0.162^{* *}$ & $\begin{array}{l}.791 \\
(.655)\end{array}$ & & $0.00 * *$ \\
\hline RI & $0.404^{* *}$ & $-0.332 * *$ & $-0.388 * *$ & $-0.417^{* *}$ & $0.422^{* * *}$ & $-0.122^{* *}$ & $0.500^{* *}$ & $\begin{array}{r}.818 \\
(692)\end{array}$ & \\
\hline $\mathrm{POF}$ & $-0.110^{* * *}$ & $0.028 * *$ & $0.133^{* *}$ & $0.193^{* *}$ & $-0.102^{* *}$ & $-0.198^{* *}$ & $0.003 * *$ & $-0.146^{* *}$ & $\begin{array}{c}.911 \\
(.723)\end{array}$ \\
\hline MV & $0.122^{* *}$ & $-0.076^{* *}$ & $-0.175^{* *}$ & $-0.124^{* *}$ & $0.109^{* *}$ & $-0.0532 * *$ & $0.010^{* * *}$ & $0.068^{* *}$ & $-0.200^{* * *}$ \\
\hline
\end{tabular}

Note: 1. Outcome control (OC), Activity control (AC), Capability control (CC), Prevention focus (PREF), Promotion focus (PROF), Organizational feedback seeking (OFS), Customer feedback seeking (CFS), Relational investment (RI), Person-organization fit (POF), MV Marker (MV).

2. Diagonals are AVE (bold) and CR.

sisted of 47 reflective indicators and 8 correlated latent factors corresponding to the 8 constructs of the study depicted in Figure 1.

The first step in the analysis was to test the hypothesized measurement relationships and evaluate the reliability and discriminant validity of the constructs. To do this, an 8-construct confirmatory factor analysis was estimated using the covariance matrix as input. Overall, the confirmatory factor model fit the data well. The chi-square (df) was 1215.55 (398), the comparative fit index (CFI) was .98, the root mean squared error approximation (RMSEA) was .063, the normed fit index (NFI) was .96, and the relative fit index (RFI) was .96 .

As indicated in Appendix A, the Cronbach alpha reliability estimates were all well above Nunnally's (1978) recommended level of .70. Fornell and Larcker's (1981) index of the average amount of variance each latent factor accounted for in its indicators ( $\mathrm{pvc}[n]$ ) was well above the recommended level of .50 for all constructs. Evidence of discriminant validity is provided by the fact that all of the construct intercorrelations 
were significantly $(\mathrm{p}<.05)$ less than 1.00 . Further, the variance shared by any two constructs (i.e., the square of their intercorrelation) was always less than the $\operatorname{pvc}(\eta)$ 's for the constructs.

To access the potential common method bias, the MV marker method, which used a scale theoretically unrelated to at least one scale in the analysis, was applied (Lindelland Whitney 2001). A 5-item scale was used to measure manager's perceived team cooperation (Cadogan et al. 2009, Cronbach's $a=0.805$ ) and selected the lowest positive correlation $(r=0.010) \mathrm{be}^{-}$ tween the MV marker and other variables to adjust the construct correlation and statistical significance (Lindell and Whitney 2001). None of the significant correlations became insignificant after adjustment (see Table 1). Therefore, common method bias was not a serious concern.

\subsection{Results and Analysis}

Using structural equation modeling with LISREL
8.5, the research hypotheses were tested (Jöreskog and Sörbom 1996). The overall fit of this model was acceptable. The chi - square (df) was 1748.35 (421), the comparative fit index (CFI) was .96, the root mean squared error approximation (RMSEA) was .078, the normed fit index (NFI) was .94, and the relative fit index (RFI) was .94.

Table 2 shows the structural estimates of this model. The analyses provide support for most hypothesized relationships.

Hypotheses 1, 2, and 3 respectively hypothesize that different types of control systems are positively associated with salespeople's regulatory focus. Hypothesis 1 states that the greater the salesperson's perceived activity control system, the greater the extent of the employee's prevention focus. Structural equation modeling supports this view through finding a positive $(\gamma=0.36, \mathrm{p}<.01)$ and significant association between the degree of activity control system and salespeople's prevention focus. Hypothesis 2 argues that salespeople's perceived outcome control system influences the extent of an em-

〈Table 2〉 Result of Hypothesized Relationships

\begin{tabular}{lcccc}
\hline \multicolumn{1}{c}{ Hypothesized relationships } & $\begin{array}{c}\text { Unstandardize } \\
\text { d Estimates }\end{array}$ & t-value & StdError & Conclusion \\
\hline Activity control $\rightarrow$ Prevention focus & 0.36 & 7.69 & 0.05 & H1 supported \\
Outcome control $\rightarrow$ Promotion focus & 0.15 & 2.20 & 0.07 & H2 supported \\
Capability control $\rightarrow$ Promotion focus & 0.41 & 5.93 & 0.07 & H3 supported \\
Prevention focus $\rightarrow$ Organization feedback seeking & -0.05 & -1.37 & 0.04 & H4 not supported \\
Promotion focus $\rightarrow$ Customer feedback seeking & 0.44 & 7.39 & 0.06 & H5 supported \\
Prevention focus $\rightarrow$ Relationship investment & -0.32 & -6.70 & 0.05 & H6 supported \\
Promotion focus $\rightarrow$ Relationship investment & 0.39 & 7.49 & 0.05 & H7 supported \\
\hline
\end{tabular}


ployee's promotion focus. The results lend strong support for this relationship in that outcome control and promotion focus $(\gamma=0.15$, $\mathrm{p}<.01)$ is positively and statistically significant. Hypothesis 3 contends that capability control system positively relates to the promotion focus of salespeople. Hypothesis 3 is strongly supported by the results in a highly significant parameter $(\gamma=0.41, \mathrm{p}<.01)$ and, therefore, is accepted.

Hypotheses 4 and 5 argue that salespeople's regulatory focus is positively related with employee's feedback seeking from different sources. Hypothesis 4 contends that a salesperson's prevention focus is positively associated with organizational feedback seeking. However, Hypothesis 4 is not supported by the results in a non-significant parameter $(\gamma=-0.05, \mathrm{p}>.1)$ and is therefore rejected. Hypothesis 5 states that the greater the salesperson's promotion focus, the greater the extent of the employee's customer feedback seeking behavior. Structural equation modeling supports this view through finding a positive $(\gamma=0.44, \mathrm{p}<.01)$ and significant association between the degree of salespeople's promotion focus and their customer feedback seeking.

Hypotheses 6 and 7 argue that salesperson's regulatory focus is inversely related with employee's relational investment. Hypothesis 6 contends that salespeople's prevention focus negatively relates to their relational investment. Hypothesis 6 is strongly supported by the re- sults in a highly significant parameter $(\gamma=$ $-0.32, \mathrm{p}<.01$ ) and is accepted. Hypothesis 7 pertains to promotion focus of salespeople and its influence on relational investment. The results indicate that salespeople who have promotion focus exhibited the predicted positive influence on their relationship investment (standardized coefficient value of $\gamma=0.39, \mathrm{p}<.01)$.

\subsection{Results of Moderating Effects of $\mathrm{P}-\mathrm{O}$ fit}

Hypotheses 8 to 11 were tested via hierarchical moderated regression analysis. As suggested by Aiken and West (1991), the variables of promotion focus, prevention focus, and person-organization fit were mean-centered to minimize the threat of multicollinearity in equations where interaction terms were created. The values of the variance inflation factor were well below the cut-off of 10, which was recommended by Neter et al. (1996).

Table 3 shows the results of our hypotheses. Hypothesis 8 posits that prevention focus would be more positively related to salespeople's organizational feedback seeking when they perceive more fit with their organization. The results of the moderated analysis demonstrate a positive and significant interaction effect of prevention focus as well as person-organizational fit on the salesperson's organizational feedback seeking $(\beta=0.443, \mathrm{p}<.01)$. These findings support Hypothesis 8, which is that salespeople 
〈Table 3〉 Moderated Regression Results from the Effect of Prevention Focus

\begin{tabular}{|c|c|c|c|c|c|c|c|}
\hline \multirow{2}{*}{$\begin{array}{l}\text { Dependent } \\
\text { Variable } \\
\text { Predictor }\end{array}$} & \multicolumn{3}{|c|}{ Organizational feedback seeking } & $\begin{array}{c}\text { Dependent } \\
\text { Variable }\end{array}$ & \multicolumn{3}{|c|}{ Relationship investment } \\
\hline & Step 1 & Step 2 & Step 3 & Predictor & Step 1 & Step 2 & Step 3 \\
\hline$P R E V$ & $-.068 * * *$ & $-.031^{* * * *}$ & $-.401 * * *$ & PREV & $-.417^{* * *}$ & $-.406 * * *$ & $-.081^{* * * *}$ \\
\hline POF & & $-.183^{* * * *}$ & $-.260 * * *$ & POF & & $-.057^{* * * *}$ & $.011^{* * * *}$ \\
\hline PREVXPOF & & & $.443^{* *}$ & PREVXPOF & & & $-.388 * * *$ \\
\hline$d f$ & 1 & 2 & 3 & Df & 1 & 2 & 3 \\
\hline$R^{2}$ & .005 & .037 & .079 & $R 2$ & .174 & .177 & .209 \\
\hline$\Delta R^{2}$ & & .032 & .042 & $\Delta R^{2}$ & & .003 & .032 \\
\hline Adjusted $R^{2}$ & .002 & .033 & .073 & Adjusted $R^{2}$ & .172 & .173 & .204 \\
\hline $\mathrm{F}$ & 2.088 & 8.560 & 12.739 & F & 94.493 & 48.161 & 39.420 \\
\hline
\end{tabular}

****ignificant at $\mathrm{p}<.01,{ }^{* *}$ Significant at $\mathrm{p}<.05$, and *Significant at $\mathrm{p}<.1$.

PREV (prevention focus) and POF (person-organization fit)

who are prevention focused are more concerned about organizational feedback when they perceive more fit with organizations.

Hypothesis 9 contends that prevention focus will be less positively related to relationship investment when salespeople perceive more fit with their organization. The result indicates that the interaction between prevention focus and $\mathrm{P}-\mathrm{O}$ fit has a significant and negative effect ( $\beta=-0.388, p>.1)$ on salesperson's relationship investment. Thus, Hypothesis 9 is supported. Table 4 shows the moderating effect of $\mathrm{P}-\mathrm{O}$ fit in the relationships among promotion focus, customer feedback seeking, and relationship

$\langle$ Table 4〉 Moderated Regression Results from the Effect of Promotion Focus

\begin{tabular}{|c|c|c|c|c|c|c|c|}
\hline \multirow{2}{*}{$\begin{array}{l}\text { Dependent } \\
\text { Variable } \\
\text { Predictor }\end{array}$} & \multicolumn{3}{|c|}{ Organizational feedback seeking } & \multirow{2}{*}{$\begin{array}{c}\text { Dependent } \\
\text { Variable } \\
\text { Predictor }\end{array}$} & \multicolumn{3}{|c|}{ Relationship investment } \\
\hline & Step 1 & Step 2 & Step 3 & & Step 1 & Step 2 & Step 3 \\
\hline$P R O M$ & $.289 * * *$ & $.295^{* * * *}$ & $.427^{* * * *}$ & PROM & $.422 * * *$ & $.412 * * *$ & $.509 * * *$ \\
\hline POF & & $.050 * * *$ & $.194^{* * *}$ & POF & & $-.092 * *$ & $.014^{* * * *}$ \\
\hline PROMXPOF & & & $-.350^{* * *}$ & PROMXPOF & & & $-.258^{* * * *}$ \\
\hline$d f$ & 1 & 2 & 3 & $d f$ & 1 & 2 & 3 \\
\hline$R^{2}$ & .084 & .086 & .175 & $R 2$ & .178 & .187 & .235 \\
\hline$\Delta R^{2}$ & & .002 & .089 & $\Delta R^{2}$ & & .008 & .048 \\
\hline Adjusted $R^{2}$ & .082 & .082 & .169 & Adjusted $R^{2}$ & .176 & .183 & .230 \\
\hline $\mathrm{F}$ & 40.841 & 21.0028 & 31.512 & $\mathrm{~F}$ & 97.347 & 51.383 & 45.711 \\
\hline
\end{tabular}

***Significant at $\mathrm{p}<.01,{ }^{* *}$ Significant at $\mathrm{p}<.05$, and *Significant at $\mathrm{p}<.1$.

PREV (prevention focus) and POF (person-organization fit) 
investment. Hypothesis 10 posits that promotion focus would be less positively related to salespeople's customer feedback seeking when they perceive more fit with their organization. The results of the moderated analysis demonstrate a negative and significant interaction effect of promotion focus and person-organizational fit on the salesperson's customer feedback seeking $(\beta=-0.350, p<.01)$. These findings support Hypothesis 10, which is salespeople who are promotion focused are less concerned about customer feedback when they perceive more fit with organizations.

Hypothesis 11contends that promotion focus will be less positively related to relationship investment when salespeople perceive more fit with their organization. The result indicates that the interaction between promotion focus and $\mathrm{P}-\mathrm{O}$ fit has significant and negative effect ( $\beta=$ $-0.258, p>1$ ) on salesperson's relationship investment. Thus, Hypothesis 11 is also supported.

\section{Discussion and Conclusion}

There is a substantial body of literature examining the management control system, both in academia and practitioner publications. Both streams agree that there is a potential effect of the management control system on salespeople's emotional and behavioral responses. Nevertheless, there are significant gaps in our understanding of management control systems. This paper attempts to fill this gap by adopting the regulatory focus theory and presenting an integrated model that explains that organizational control systems prime the salesperson's goal orientation (a prevention focus vs. a promotion focus). Though, a focus on promotion and prevention may not be the only motivations influencing sales employees'behavior, the present results suggest that these motivations offer crucial insight into how employees react in the different management control systems.

A research model was developed to explain the effect of control systems on sales force behavioral responses based on the regulatory focus and regulatory fit theories. This study explains how different types of salesperson's regulatory focus are built based on their perceived control systems. Even though, regulatory focus research is predominantly concentrated on the behavior of individuals, in many cases people's behavior at the group level cannot simply be inferred from an individual level consideration. Faddegonet al. (2008) argue that membership in a group influences the regulatory focus strategies used by group members in ways that cannot be simply deduced from their individual regulatory focus inclinations.

A significant contribution that our model makes is suggesting that a salesperson's regulatory focus acts as a mediator and its effects are on different types of sales-related behavior. According to the rapid change in the market environment, 
the growth in popularity of relationship marketing has been explained. It underscores the importance of building long-term relationships with customers. This research shows that salesperson's regulatory focus is affected by different control systems, and this goal orientation leads to different sales-related behaviors that can affect relationship building with customers. Thus, managers must understand the effect of control systems on their employees' behaviors and provide appropriate control systems to meet organizational goals.

We enhance our model by examining the person-organization fit as a moderator on the effect of salesperson's regulatory focus and behavioral responses based on regulatory fit theory. Generally, salespeople have no power to change their control systems, and their sales behaviors are shaped by this system. However, the perceived fit with their organizations may enhance or weaken the effects of the regulatory focus on sales-related behaviors. Thus, if managers are not able to change their organizational control systems, they can reduce the negative effects of salesperson's goal orientation by monitoring and increasing salesperson's $\mathrm{P}-\mathrm{O}$ fit.

\subsection{Limitations and Future Research}

The current study has some limitations that should be mentioned. Most importantly, the findings come from a cross-sectional study. Therefore, although this study claimed to study processes in employees' well-being, it is not possible to draw conclusions about the causal relationships among the study variables. Longitudinal study designs are needed to examine the proposed processes.

In this research, this study examined the effects of three types of control systems that were suggested by Challagalla and Shervani (1996) on the salesperson's regulatory focus. However, there are differences on how management control in marketing and sales has been conceptualized, so it is useful to examine the alternative control philosophies. For example, Jaworski (1988) proposes formal (output-and process-controls) and informal forms (social-, cultural-, and self-control) of management control. Brashear et al. (2005) suggested process and decision control as antecedents of salesperson trust. Flaherty et al. (2007) evaluated four different types of control - output, process, self, and professional. By adopting the different concepts of managementcontrol system, we can increase our understanding of the relationship between management control and employee's regulatory focus.

Not only are there different types of control system but there are also different organizational contexts or cultures that can be leading factor of an employee's regulatory focus. For example, a firm's innovative culture or open-mindness can be a positive antecedent of an employee's promotion focus and negative leading factor of prevention focus. Managers' leadership styles also can be regarded as potential influential varia- 
bles of an employee's regulatory focus.

Based on the regulatory fit theory, the moderating effect of a salesperson's $\mathrm{P}-\mathrm{O}$ fit in the links between regulatory focus and employee's behavioral responses were examined. For future research, a match or mismatch between managers' and employees' regulatory focus can be potential moderators in the link between a salesperson's regulatory focus and behavioral responses. People who experience greater regulatory fit, and therefore derive greater value from fit, are more inclined toward goal pursuit. That is, as fit increases, people become more motivated to put forth effort toward achieving their goal and focus their attention on goal attainment. In addition, when regulatory fit is higher, their evaluations of goal pursuits, and that which enables their goal pursuits, will be more positive as well (Benjamin and Flynn 2006).

Finally, this study investigated a theoretical model using samples from the various banks and insurance companies in South Korea, but the generalizability of the findings cannot be extrapolated beyond this context.

〈Received January 13. 2015〉

〈Revised April 15. 2015〉

$\langle$ Accepted April 23. 2015〉

\section{References}

Aiken, Leona S. and Stephen G. West (1991),
Multiple regression: Testing and interpreting interactions, Newbury Park, CA: Sage.

Anderson, Erin and Richard L. Oliver (1987), "Perspectives on behavior-based versus outcome-based sales force control systems," Journal of Marketing, 51 (4), 76-88.

Benjamin, Lily and Flynn J. Flynn(2006), "Leadership style and regulatory mode: Value from fit?” Organizational Behavior and Human Decision Processes, 100 (2), 216-230.

Brashear, Thomas G, Chris Manolis, and Charles M. Brooks (2005), "The effects of control, trust, and justice on salesperson turnover," Journal of Business Research, 58 (3), 241249.

Brockner, J., Troy E. Higgins, and Murray B. Low (2004), "Regulatory focus theory and the entrepreneurial process," Journal of Business Venturing, 19 (2), 203-220.

Cadogan, John W., Nick Lee, Anssi Tarkiainen, and Sanna Sundqvist (2009), "Sales manager and sales team determinants of salesperson ethical behavior," European Journal of Marketing, 43 (7/8), 907-937.

Callister, Ronda R., Michael W. Kramer, and Daniel B. Turban (1999), "Feedback seeking following career transitions," Academy of Management Journal, 42 (4), 429-438.

Challagalla, Goutam N. and Tasadduq A. Shervani (1996), "Dimensions and types of supervisory control: Effects on salesperson performance and satisfaction," Journal of 
Marketing, 60 (1), 89-105.

Das, T. K., and Rajesh Kumar (2011), "Regulatory focus and opportunism in the alliance development process, Journal of Management, 37 (3), 682-708.

De Wulf Kristof, Gaby Odekerken-Schroder, and Dawn Lacobucci (2001), "Investments in consumer relationships: A cross-country and cross-industry exploration," Journal of Marketing, 65(4), 33-50.

Faddegon Krispijn, Naomi Ellemers, and Dann Scheepers (2009), "Eager to be the best, or vigilant not to be the worst: The emergence of regulatory focus in disjunctive and conjunctive group tasks," Group Process and Intergroup Relations, 12 (5), 653-671.

Faddegon Krispijn, Daan Scheepers and Naomi Ellemers (2008), "If we have the will, there will be a way: Regulatory focus as a group identity," European Journal of Social Psychology, 38 (5), 880-895.

Fang, Eric, Kenneth R. Evans, and Shaoming Zou (2005), "The moderating effect of goalsetting characteristics on the sales control systems-job performance relationship," Journal of Business Research, 58 (9), 1214-1222.

Flaherty, Karen E., Todd, J. Arnold, and Shane C. Hunt (2007), "The influence of the selling situation on the effectiveness of control: Toward a holistic perspective," Journal of Personal Selling and Sales Management, 27 (3), 221-233.

Florack, Arnd, and Juliane Hartmann (2007),
"Regulatory focus and investment decisions in small groups," Journal of Experimental Social Psychology, 43 (4), 626-632.

Fornell, Claes and David F. Larker (1981), "Evaluating structural equation models with unobservable variables and measurement error," Journal of Marketing Research, 18 (1), 39-50.

Förster, Jens, Tory E. Higgins, and Lorraine Chen Idson (1998), “Approach and avoidance strength during goal attainment: Regulatory focus and the goal looms larger effect," Journal of Personality and Social Psychology, 75 (5), 1115-1131.

Ganesan, Shanker (1994), "Determinants of longterm orientation in buyer-seller relationships," Journal of Marketing, 58 (2), 1-19.

Heide, Jan B. and Rodney L. Stump (1995), "Performance implications of buyer-supplier relationships in industrial markets: A transaction cost explanation," Journal of Business Research, 32 (1), 57-66.

Higgins, E. Tory (1997), “Beyond Pleasure and Pain," American Psychologist, 52 (12), 1280-1300.

Higgins, E. Tory (1998), "Promotion and prevention: Regulatory focus as a motivational principle,”In M. P. Zanna (Ed.), Advances in experimental psychology (pp. 1-46). New York: Academic Press.

Higgins, E. Tory (2000), "Making a good decision: Value from fit," American Psychologist, 55 (11), 1217-1230. 
Higgins, E. Tory, Christopher J. R. Roney, Crowe Ellen, and Charles Hymes (1994), "Ideal versus ought predilections for approach and avoidance: Distinct self-regulatory systems," Journal of Personality and Social Psychology, 66 (2), 276-286.

Hofstede, G. (1980), Culture's consequences: International differences in work-related values, London: Sage.

Jaworski, Bernard J. (1988), “Toward a theory of marketing control: Environmental context, control types and consequences," Journal of Marketing, 52 (3), 23-39.

Jaworski, Bernard J., Vlasis Stathakopoulos, and H. Shanker Krishnan (1993), "Control combinations in marketing: Conceptual framework and empirical evidence," Journal of Marketing, 57 (1), 57-69.

Jonas, Kai J., Kai Sassenberg, and Daan Scheepers (2010), "Self-regulation within and between groups," Group Processes and Intergroup Relations, 13 (2), 131-136.

Jöreskog, Karl G. and Dag Sörbom (1996), LISREL 8: User's reference guide, Chicago, IL: Scientific Software International.

Kark, Ronit and Dina Van Dijk (2007), "Motivation to lead, motivation to follow: The role of the self-regulatory focus in leadership processes," Academy of Management Review, 32 (2), 500-528.

Kim, Ji Yoon (2014), "The effect of regulatory focus on the link between purchase behavior and redemption behavior," Asia Mar- keting Journal, 15 (4), 51-60.

Kohli, Ajay K., Tasadduq A. Shervani and Goutam N. Challagalla (1998), "Learning and performance orientation of salespeople: the role of supervisors," Journal of Marketing Research, 35 (2), 263-274.

Lee, Angela Y., and Jennifer L. Aaker (2004), "Bringing the frame into focus: The influence of regulatory fit on processing fluency and persuasion," Journal of Personality and Social Psychology, 86, 205-218.

Lee, Ihn Goo and Seong Goo Ji (2013), “A study on the role of locomotion orientation as an antecedent of salespeople' selling ebhavior," Asia Marketing Journal, 15 (4), 51-60.

Levine, John M., E. Troy Higgins, and HoonSeok Choi (2000), "Development of strategic norms in groups," Organizational Behavior and Human Decision Processes, 82 (1), 88-101.

Lindell, Michael K. and David J. Whitney (2001), "Accounting for common method variance in cross-sectional research design," Journal of Applied Psychology, 86 (2), 114-121.

Lord, Robert G. and Karen J. Maher (1990), "Alternative information processing models and their implications," Academy of $\mathrm{Ma}^{-}$ nagement Review, 15 (1), 9-28.

Mallin, Michael L. and Ellen B. Pullins (2009), "The moderating effect of control systems on the relationship between commission and salesperson intrinsic motivation in a 
customer oriented environment," Industrial Marketing Management, 38 (7), 769-777. Miao, Fred C. and Kenneth R. Evans (2007), "The role of salesperson motivation in sales control systems-Intrinsic and extrinsic motivation revisited," Journal of Business Research, 60 (5), 417-425.

Netemeyer, Richard G., James S. Boles, Daryl O. McKee, and Robert McMurrian (1997), "An investigation into the antecedents of organizational citizenship behaviors in a personal selling context," Journal of Marketing, 61 (3), 85-98.

Neter, John, Michael H. Kutner, Christopher J. Nachtsheim, and William Wasserman (1996), Applied linear statistical models (4th ed.). Chicago: Irwin.

Neubert, Mitchell J., Michele K. Kacmar, Dawn S. Carlson, Lawrence B. Chonko, and James A. Roberts (2008), "Regulatory focus as a mediator of the influence of initiating structure and servant leadership on employee behavior," Journal of Applied Psychology, 93 (6), 1220-1233.

Nunnally, JumC. (1978).Psychometric Theory. New York: McGraw-Hill.

Oliver, Richard L. and Erin Anderson(1994), "An empirical test of the consequences of behavior- and outcome-based sales control systems," Journal of Marketing, 58 (4), 53-67.

Oliver, Richard L. and Erin Anderson (1995), "Behavior- and outcome-based sales control systems: Evidence and consequences of pure-form and hybrid governance," Journal of Personal Selling and Sales Management, 15 (4), 1-15.

Onyemah, Vincent (2005), "How inconsistent sales force control systems hinder sales and marketing objectives," MSI Board of Trustees' Meeting, April, 14-15, Boston.

Palmatier, Robert W., Rajiv P.Dant, Dhruv Grewal, and Kenneth R. Evans (2006), "Factors influencing the effectiveness of relationship marketing: A meta-analysis," Journal of Marketing, 70 (4), 136-158.

Piercy, Nigel F., David W. Cravens, Nikala Lane, and Douglas W. Vorhies (2006), "Driving organizational citizenship behaviors and salesperson in-role behavior per of performance: the role of management control and perceived organizational support," Journal of the Academy of Marketing Science, 34 (2), 244-262.

Rietzschel, Eric F. (2011), “Collective regulatory focus predicts specific aspects of team innovation," Group Process and Intergroup Relations, 14 (3), 337-345.

Scott, Susanne G. and Bruce, A. Reginald (1994), "Determinants of innovative behavior: A path model of individual innovation in the workplace," Academy of Management Journal, 37 (3), 580-607.

Shah, James Y., Paize C. Brazy, and Tory E. Higgins (2004), "Promoting us or preventing them: Regulatory Focus and Manifestations 
of Intergroup Bias," Personality and Social Psychology Bulletin, 30 (4), 433-446.

Shah, James Y. and Tory E. Higgins (1997), "Expectancy X value effects: Regulatory focus as determinant of magnitude and direction," Journal of Personality and Social Psychology, 73 (3), 447-458.

Shah, James Y., Tory E. Higgins, and Ronald S. Friedman (1998), "Performance incentives and means: How regulatory focus influences goal attainment," Journal of Personality and Social Psychology, 74 (2), 285-293.

Wallace, Craig J., PaulD. Johnson, and Lance M. Frazier (2009), "An examination of the factorial, construct, and predictive validity and utility of the regulatory focus at work scale," Journal of Organizational Behavior, 30 (6), 805-831.

Wallace, Craig J. and Gilad Chen, (2005), "Development and validation of a workspecific measure of cognitive failure: Implications for occupational safety," Journal of Occupational and Organizational Psychology, 78 (4), 615-632.
Wallace, Craig J. and Gilad Chen, (2006), “A multilevel integration of personality, climate, self-regulation, and performance," Personal Psychology, 59 (3), 529-557.

Webster Frederick E., Alan J. Malter, and Shanker Ganesan(2003), Can marketing regain its seat at the table? Report No. 03-003. Cambridge, MA: Marketing Science Institute.

Wu, Cindy, Jeffrey M. McMullen, Mitchell J. Neubert and Xiang Yi (2008), "The influence of leader regulatory focus on employee creativity," Journal of Business Venturing, 23 (5), 587-602.

Zhou Rongrong and Michael T. Pham (2004), "Promotion and prevention across mental accounts: When financial products dictate consumers' investment goals," Journal of Consumer Research, 31 (1), 125-135.

Zohar, Dov (2000), “A group-level model of safety climate: Testing the effect of group climate on micro accidents in manufacturing jobs," Journal of Applied Psychology, 85 (4), 587-596. 


\section{〈Appendix〉}

\section{Measurement Items and $\mathrm{CFA}$ results}

\begin{tabular}{|c|c|c|c|c|c|}
\hline \multirow{2}{*}{ Construct } & \multirow{2}{*}{ Loading } & \multicolumn{4}{|c|}{ Path } \\
\hline & & Loading & $\mathrm{C} / \mathrm{R}$ & Reliability & AVE \\
\hline $\begin{array}{l}\text { Outcome control } \\
\text { (Miao et al. 2007) }\end{array}$ & $\begin{array}{l}\text { 1. My manager tells me about the } \\
\text { expected level of achievement on sales } \\
\text { volume or market share targets. } \\
\text { 2. My manager monitors my performance } \\
\text { on achieving sales volume or market } \\
\text { share targets. } \\
\text { 3. I receive frequent feedback about } \\
\text { whether I am meeting expected } \\
\text { achievement levels on sales volume or } \\
\text { market share targets. } \\
\text { 4. My manager ensures that I am aware } \\
\text { of the extent to which I attain sales } \\
\text { volume or market share targets. } \\
\text { 5. I would be recognized by my manager } \\
\text { if I performed well on sales volume or } \\
\text { market share targets. }\end{array}$ & $.82-.87$ & .888 & .908 & .727 \\
\hline $\begin{array}{l}\text { Activity control } \\
\text { (Miao et al. 2007) }\end{array}$ & $\begin{array}{l}\text { 1. My manager informs me about the } \\
\text { sales/services activities I am expected } \\
\text { to perform. } \\
\text { 2. My manager monitors how I perform } \\
\text { required sales/services activities. } \\
\text { 3. My manager informs me about whether } \\
\text { I meet his/her expectations on } \\
\text { sales/services activities. } \\
\text { 4. My manager readjusts my sales/services } \\
\text { activities when necessary. } \\
\text { 5. I would be recognized by my manager } \\
\text { if I perform sales/services activities well. }\end{array}$ & $.87-.93$ & .942 & .929 & .805 \\
\hline $\begin{array}{l}\text { Capability control } \\
\text { (Miao et al. 2007) }\end{array}$ & $\begin{array}{l}\text { 1. My manager periodically evaluates the } \\
\text { selling skills I use to accomplish a task } \\
\text { (e.g., how I negotiate). } \\
\text { 2. My manager provides guidance on ways } \\
\text { to improve my selling skills and abilities. } \\
\text { 3. My manager evaluates how I make } \\
\text { sales presentations and communicate } \\
\text { with customers. } \\
\text { 4. My manager assists me by illustrating } \\
\text { why using a particular sales/services } \\
\text { approach may be effective. } \\
\text { 5. I would be commended if I improved } \\
\text { my selling/servicing skills. }\end{array}$ & $.78-.87$ & .899 & .887 & .691 \\
\hline
\end{tabular}


(continue)

\begin{tabular}{|c|c|c|c|c|c|}
\hline \multirow{2}{*}{ Construct } & \multirow{2}{*}{ Loading } & \multicolumn{4}{|c|}{ Path } \\
\hline & & Loading & $\mathrm{C} / \mathrm{R}$ & Reliability & AVE \\
\hline $\begin{array}{l}\text { Prevention focus } \\
\text { (Wallace and Chen } \\
\text { 2005) }\end{array}$ & $\begin{array}{l}\text { 1. I focus on following rules and } \\
\text { regulations at work. } \\
\text { 2. I focus on completing work tasks } \\
\text { correctly. } \\
\text { 3. I focus on doing my duty at work. } \\
\text { 4. I focus on my work responsibilities. } \\
\text { 5. I focus on fulfilling my work obligations. } \\
\text { 6. I focus on the details of my work. }\end{array}$ & $.74-.89$ & .930 & .884 & .728 \\
\hline $\begin{array}{l}\text { Promotion focus } \\
\text { (Wallace and Chen } \\
\text { 2005) }\end{array}$ & $\begin{array}{l}\text { 1. I focus on accomplishing a lot at work. } \\
\text { 2. I focus on getting my work done no } \\
\text { matter what. } \\
\text { 3. I focus on getting a lot of work finished } \\
\text { in a short amount of time. } \\
\text { 4. I focus on work activities that allow me } \\
\text { to get ahead at work. } \\
\text { 5. I focus on my work accomplishments. } \\
\text { 6. I focus on how many job tasks I can } \\
\text { complete. }\end{array}$ & $.69-.83$ & .912 & .893 & .677 \\
\hline $\begin{array}{l}\text { Person-organization } \\
\text { fit } \\
\text { (Netemeyer et al. } \\
\text { 1997) }\end{array}$ & $\begin{array}{l}\text { 1. I identify strongly with the goals of my } \\
\text { organization. } \\
\text { 2. My personal goals and the goals of my } \\
\text { organization are very similar. } \\
\text { 3. I don't care about the goals of this } \\
\text { organization as much as many of my } \\
\text { co-workers do. (r) } \\
\text { 4. The things that I value in life are very } \\
\text { similar to the things that my } \\
\text { organization values. } \\
\text { 5. My personal values match my } \\
\text { organization's values and culture. } \\
\text { 6. My organization's values and culture } \\
\text { provide a good fit with the things that I } \\
\text { value in life. }\end{array}$ & $.73-.95$ & .911 & .854 & .723 \\
\hline $\begin{array}{l}\text { Organizational } \\
\text { feedback seeking } \\
\text { (Callister et al. } \\
\text { 1999) }\end{array}$ & $\begin{array}{l}\text { 1. I ask my supervisor how I am doing. } \\
\text { 2. I ask my supervisor if I am meeting all } \\
\text { my job requirements. } \\
\text { 3. From watching my supervisor, I can tell } \\
\text { how well I am performing my job. } \\
\text { 4. From watching my supervisor's reaction } \\
\text { to what I do, I can tell how well my } \\
\text { supervisor thinks I am doing. }\end{array}$ & $.72-.91$ & .915 & .860 & .844 \\
\hline
\end{tabular}


(continue)

\begin{tabular}{|c|c|c|c|c|c|}
\hline \multirow{2}{*}{ Construct } & \multirow{2}{*}{ Loading } & \multicolumn{4}{|c|}{ Path } \\
\hline & & Loading & $\mathrm{C} / \mathrm{R}$ & Reliability & AVE \\
\hline $\begin{array}{l}\text { Customer feedback } \\
\text { seeking } \\
\text { (Callister et al. } \\
\text { 1999) }\end{array}$ & $\begin{array}{l}\text { 1. I regularly monitor my customers' } \\
\text { satisfaction level. } \\
\text { 2. I pay close attention to after-sales } \\
\text { service. } \\
\text { 3. I encourage informal feedback regarding } \\
\text { my services. } \\
\text { 4. I ask my customers to evaluate the } \\
\text { quality of my work and service. }\end{array}$ & $.77-.85$ & .791 & .818 & .655 \\
\hline $\begin{array}{l}\text { Relationship } \\
\text { investment } \\
\text { (De Wulf et al. } \\
\text { 2001) }\end{array}$ & $\begin{array}{l}\text { 1. I make efforts to increase regular } \\
\text { customers' loyalty. } \\
\text { 2. I make various efforts to improve my } \\
\text { tie with regular customers. } \\
\text { 3. I really care about keeping regular } \\
\text { customers. }\end{array}$ & $.81-.83$ & .818 & .815 & .692 \\
\hline
\end{tabular}

